DOI: $10.29303 /$ jrpb.v9i2.241

ISSN 2301-8119, e-ISSN 2443-1354

Tersedia online di http://jrpb.unram.ac.id/

\title{
IDENTIFIKASI JENIS KOPI MENGGUNAKAN SENSOR E-NOSE DENGAN METODE PEMBELAJARAN JARINGAN SYARAF TIRUAN BACKPROPAGATION
}

\author{
Identification of Coffee Types using E-Nose Sensor with Backpropagation \\ Artificial Neural Network Learning Method
}
Dwi Dian Novita ${ }^{*}$, Akhmad Bangsawan Sesunan', Mareli Telaumbanua1, Sugeng Triyono ${ }^{1}$, Tri Wahyu Saputra ${ }^{2}$

\author{
${ }^{1}$ Jurusan Teknik Pertanian, Fakultas Pertanian, Universitas Lampung \\ Jl. Prof. Dr. Ir. Sumantri Brojonegoro, Bandar Lampung, Lampung, Indonesia \\ ${ }^{2}$ Jurusan Agroteknologi, Fakultas Pertanian, Universitas Jember \\ Jember, Jawa Timur, Indonesia
}

Email $^{*}$ ): dwi.diannovita@fp.unila.ac.id atau ddnovita.08@gmail.com

Diterima: Juli 2021

Disetujui: September 2021

\begin{abstract}
Electronic Nose is a tool that can imitate the workings of the human nose. Coffee has several types including robusta coffee, arabica coffee and luwak coffee. Each type of coffee has its own distinctive aroma, so a tool is needed to differentiate it quickly and precisely. This study aims to identify the types of coffee based on the different aromas contained. This study used Lampung's natural robusta coffee beans (coffee 1), natural robusta (coffee 2), semi-wash robusta (coffee 3), natural arabica (coffee 4), fullwash arabica (coffee 5). The research used JST backpropagation method with a network architecture of 1 input, 2 hidden layers, and 1 Output. The best activation function in the JST model training is logsig-logsig-tansig with an RMSE value of 0.003602368 and $R^{2}$ of 0.991. The classification results of coffee types using the E-Nose sensor with the JST Backpropagation method showed the percentage of successful identification of 5 types of coffee, that is: 100\% natural robusta Lampung coffee, $100 \%$ natural robusta coffee, $72 \%$ semiwash robusta coffee, $100 \%$ natural arabica coffee, and coffee arabica fullwash $100 \%$.
\end{abstract}

Keywords: E-Nose; Artificial Neural Network; coffee; microcontroller

\begin{abstract}
ABSTRAK
Electronic Nose merupakan sebuah alat yang dapat menirukan cara kerja hidung manusia. Kopi memiliki beberapa jenis antara lain kopi robusta, kopi arabika dan kopi luwak. Setiap jenis kopi memiliki aroma khas tersendiri sehingga dibutuhkan suatu alat untuk dapat membedakannya secara cepat dan tepat. Penelitian ini bertujuan untuk mengidentifikasi jenis - jenis kopi berdasarkan perbedaan aroma yang terdapat didalamnya. Penelitian ini menggunakan biji kopi natural robusta Lampung (kopi 1), robusta natural (kopi 2), robusta semiwash (kopi 3), natural arabika (kopi 4), arabika fullwash (kopi 5). Penelitian menggunakan metode JST backpropagation dengan arsitektur jaringan 1 input, 2 hidden
\end{abstract}


layer, dan 1 Output. Fungsi aktivasi terbaik pada pelatihan model JST adalah logsig-logsigtansig dengan nilai RMSE sebesar 0,003602368 dan $\mathrm{R}^{2}$ sebesar 0,991 . Hasil klasifikasi jenis kopi menggunakan sensor E-Nose dengan metode JST Backpropagation menunjukkan persentase keberhasilan identifikasi 5 jenis kopi, yaitu: kopi natural robusta lampung yaitu $100 \%$, kopi natural robusta $100 \%$, kopi robusta semiwash $72 \%$, kopi arabika natural 100\%, dan kopi arabika fullwash $100 \%$.

Kata kunci: E-Nose; Jaringan Syaraf Tiruan; kopi; mikrokontroler

\section{PENDAHULUAN}

Kopi merupakan salah satu komoditas hasil perkebunan yang banyak dinikmati di kalangan masyarakat. Produk yang terbuat dari kopi sangat diminati oleh masyarakat sehingga semakin banyak usaha masyarakat yang menyediakan produk olahan kopi. Kopi memiliki beberapa jenis antara lain kopi robusta, kopi arabika dan kopi luwak. Kafein merupakan salah satu kandungan senyawa dalam kopi. Senyawa ini pada kondisi tubuh yang normal memiliki beberapa khasiat salah satunya yaitu merupakan obat analgetik yang mampu menurunkan rasa sakit dan mengurangi demam (Arwangga, et al., 2016). Kandungan gas amonia, hidrogen sulfida, dan karbonmonoksida pada kopi arabika lebih tinggi dibandingkan kopi robusta (Rabersyah, 2016). Untuk dapat mengenali jenis kopi perlu diketahui perbedaan pada setiap jenis kopi yang ingin diketahui seperti warna, tekstur, aroma dan juga kualitas rasanya (Toko, 2000). Terdapat tiga jenis pemalsuan pada kopi yaitu, pemalsuan dengan mencampur kopi dengan sekam kopi, jerami, jagung dan kedelai, sehingga dibutuhkan suatu teknologi yang dapat mengenali kopi (Briandet, et al., 1996).

Berdasarkan permasalahan tersebut maka dibutuhkan teknologi yang dapat digunakan untuk mengetahui jenis kopi secara cepat dan akurat yang akan diperjualbelikan sehingga mengurangi peluang terjadinya penipuan serta mempermudah mengidentifikasi kopi tersebut. E-Nose dengan metode JST backpropagation merupakan salah satu cara untuk mengidentifikasi jenis kopi secara cepat dan lebih efisien karena bentuknya yang dirancang portable sehingga dapat membantu dalam mengidentifikasi jenisjenis kopi yang ada di pasaran.

Pengembangan E-Nose umumnya menggunakan mikrokontroler sebagai pengolah informasi digital dan analog. Penggunaan mikrokontroler dalam rancangbangun sistem E-Nose disebabkan karena kecepatan akusisi dan pengolahan informasi yang unggul dan stabil. Saat ini, banyak tipe mikrokontroler yang tersemat dalam board arduino. Mikrokontroler pada board Arduino berfungsi sebagai pusat pengolah data atau Central Proccesing Unit (CPU), yang memiliki tugas mengolah semua data masuk dan data keluar. Bagian ini bertugas memeriksa input dari keypad berupa kode dan memberikan perintah ke bagian LED, dan relay (Guntoro \& Somantri, 2013). Kelebihan yang lainnya mikrokontroler dapat mengkonversi sinyal analog menjadi digital (ADC) (Lelono \& Chairiawan, 2013).

Electronic Nose (E-Nose) merupakan sebuah alat yang meniru cara kerja hidung manusia. Electronic Nose disusun oleh beberapa sensor gas yang memiliki fungsi mendeteksi bau/aroma yang meniru struktur larik syaraf penciuman dalam olfaktori manusia. Keluaran E-Nose dapat berupa pola-pola yang mewakili masingmasing bau/aroma sehingga dapat diterapkan untuk identifikasi, perbandingan, kuantifikasi dan klasifikasi berdasarkan aroma (Telaumbanua, et al., 2021; Baskara, et al., 2016). Berbagai reseptor yang dapat mengidentifikasi aroma bau terdapat di dalamnya. Reseptor ini fungsinya digantikan oleh sensor pada teknologi E-Nose. Setiap reseptor 
memberikan respon yang berbeda dari uap aroma yang sama (Kusumadewi, 2004). Perangkat ini telah mengalami banyak pengembangan serta digunakan untuk memenuhi kebutuhan industri dan lain-lain (Sitohang, 2012).

Jaringan Syaraf Tiruan (JST) tercipta sebagai suatu generalisasi model matematis dari pemahaman manusia (human cognition) yang didasarkan atas asumsi bahwa pemrosesan informasi terjadi pada elemen sederhana yang disebut neuron. Isyarat mengalir di antara sel saraf atau neuron melalui suatu sambungan penghubung. Sambungan penghubung memiliki bobot yang bersesuaian. Sel saraf merupakan fungsi aktivasi terhadap isyarat hasil penjumlahan berbobot yang masuk kepadanya untuk menentukan isyarat keluarannya (Wuryandari \& Afrianto, 2012). JST merupakan salah satu teknik yang banyak digunakan untuk masalah pengenalan karakter dan merupakan classifier yang kuat karena tingkat perhitungan dan keakuratannya yang tinggi (Matondang, 2013). JST tidak diprogram untuk menghasilkan keluaran tetentu. Semua keluaran atau kesimpulan yang dihasilkan oleh jaringan berdasarkan pada pengalaman selama proses pembelajaran (Puspitaningrum, 2006). JST mampu melakukan pengenalan kegiatan berbasis data masa lalu. Data masa lalu akan dipelajari oleh JST dan menghasilkan kemampuan untuk memberikan keputusan terhadap data yang belum pernah dipelajari (Fitryadi \& Sutikno, 2016).

\section{METODE PENELITIAN}

\section{Alat dan Bahan}

Peralatan yang digunakan dalam penelitian ini adalah chamber, sensor TGS826 (sensor 1), sensor MQ136 (sensor 2), sensor TGS813 (sensor 3), sensor TGS2602 (sensor 4), Mikrokontroler Atmega 2560, LCD Karakter 16 x 2, Power Supply, kamera, kipas angin dan alat tulis. Bahan yang digunakan dalam penelitian ini adalah biji kopi natural robusta Lampung (kopi 1), robusta natural (kopi 2), robusta semiwash (kopi 3), natural arabika (kopi 4), arabika fullwash (kopi 5).

\section{Prosedur Kerja}

Metode yang dilakukan pada penelitian ini menggunakan Jaringan Syaraf Tiruan model Backpropagation. Prosedur penelitian dimulai dengan mencari sumber pustaka tentang identifikasi jenis kopi menggunakan E-Nose. Proses pengambilan data kopi yaitu dengan meletakan kopi pada chamber yang telah disiapkan, aroma yang akan keluar akan ditangkap menggunakan sensor E-Nose dan diteruskan ke dalam mikrokontroler menjadi sinyal analog yang dikonversi menjadi sinyal digital (Telaumbanua, et al., 2021). Beberapa jenis kopi yang digunakan antara lain kopi robusta natural, robusta semiwash, arabika natural, arabika fullwash, dan robusta natural Lampung. JST dapat mengolah data yang telah didapat yang berupa sinyal ADC pada setiap jenis kopi.

Prosedur kerja alat ini, yaitu biji kopi dimasukkan pada wadah pengujian. Setelah alat diaktifkan, sensor pada wadah pengujian akan melakukan identifikasi aroma biji kopi. Empat unit sensor gas dipasang di dalam wadah pengujian yang berguna untuk mendeteksi aroma biji kopi. Sensor akan terus memonitoring perubahan bau yang terjadi pada wadah pengujian tersebut. Data sensor yang termonitoring kemudian disimpan ke dalam PC pengguna dalam bentuk format .txt. Data tersebut digunakan untuk menjadi data input untuk proses identifikasi menggunakan jaringan saraf tiruan pada software Matlab. Hasil pembelajaran akan terus dilakukan pada proses identifikasi hingga sistem dapat mendeteksi bau kopi yang sesuai berdasarkan input kopi yang diuji. Proses tersebut berakhir saat hasil identifikasi sesuai dengan target yang diinginkan $($ Output $=$ Target $)$. Proses ini akan terus menerus berulang hingga didapatkan identifikasi jenis kopi berdasarkan tingkat aroma yang dikeluarkan kopi tersebut yang berhasil dideteksi oleh sensor. 
JST dirancang dengan mengganti nilai node dan fungsi aktifasi untuk mendapatkan komposisi terbaik dengan melihat $\mathrm{R}^{2}$ terbesar dan RMSE terkecil. Bobot dan bias akan didapatkan setelah mendapatkan nilai $\mathrm{R}^{2}$ dan RMSE dari proses JST. Bobot dan bias digunakan sebagai konstanta perhitungan untuk membuat model matematika yang akan diintegrasi ke dalam program arduino untuk melakukan validasi. Validasi merupakan tahap akhir dari penelitian ini yaitu dengan melakukan pengambilan data kembali dengan menggunakan program yang telah didapat dari hasil JST untuk mengetahui tingkat keberhasilan alat dalam mendeteksi kopi.

\section{Nilai Analog to Digital Converter (ADC)}

Sensor analog adalah sensor yang menghasilkan sinyal Output analog yang kontinu atau berkelanjutan. Sinyal analog adalah sinyal data dalam bentuk gelombang kontinyu, yang memiliki parameter amplitudo dan frekuensi. Frekuensi adalah jumlah getaran putaran ulang sinyal analog dalam satu siklus lengkap per satuan detik. Nilai ADC adalah nilai sinyal analog yang didapat dari pengubahan nilai masukan data tegangan listrik atau sinyal lainnya menjadi nilai keluaran sinyal digital (angka). ADC banyak digunakan sebagai pengatur proses industri, komunikasi digital, rangkaian pengukuran dan pengujian. Biasanya ADC digunakan untuk perantara antara sensor analog dengan sistem komputer seperti sensor suhu, tekanan, cahaya, berat, atau yang lainnya, kemudian diukur dengan menggunakan sistem digital komputer (Ikhsan, 2018).

\section{Perancangan Jaringan Syaraf Tiruan (JST)}

Pada perancangan software dirancang gambaran pemograman sistem dan desain aplikasi yang akan digunakan untuk melakukan perintah-perintah tertentu agar Output sistem dapat bekerja sesuai dengan program yang telah dibuat. Perancangan program ini menggunakan software Matlab.
Jaringan Syaraf Tiruan disusun dengan menentukan arsitektur jaringan terlebih dahulu, sebagai langkah untuk mempermudah proses kalibrasi dan validasi identifikasi jenis kopi. Arsitektur jaringan dapat dilihat pada Gambar 1.

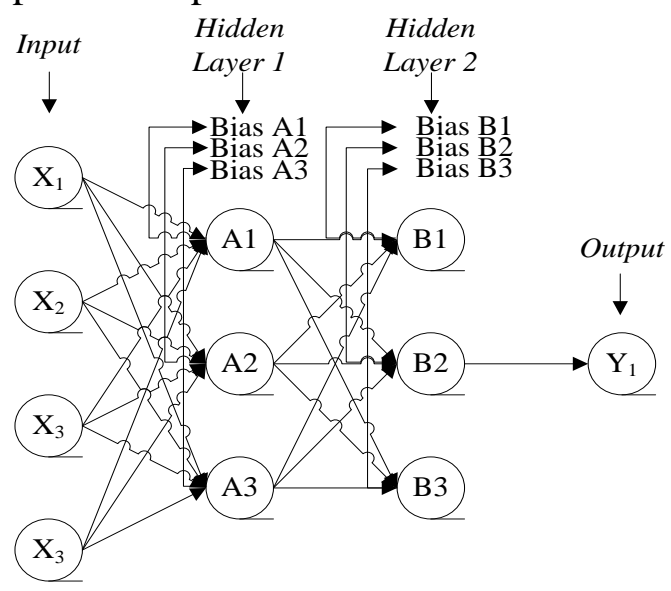

Gambar 1. Diagram arsitektur jaringan

Perancangan JST terdapat dua proses yang harus dilakukan yaitu proses pelatihan dan proses pengujian. Proses Backpropagation terdiri dari beberapa proses yang dapat di lihat pada Gambar 2 tentang diagram alir dari Backpropagation.

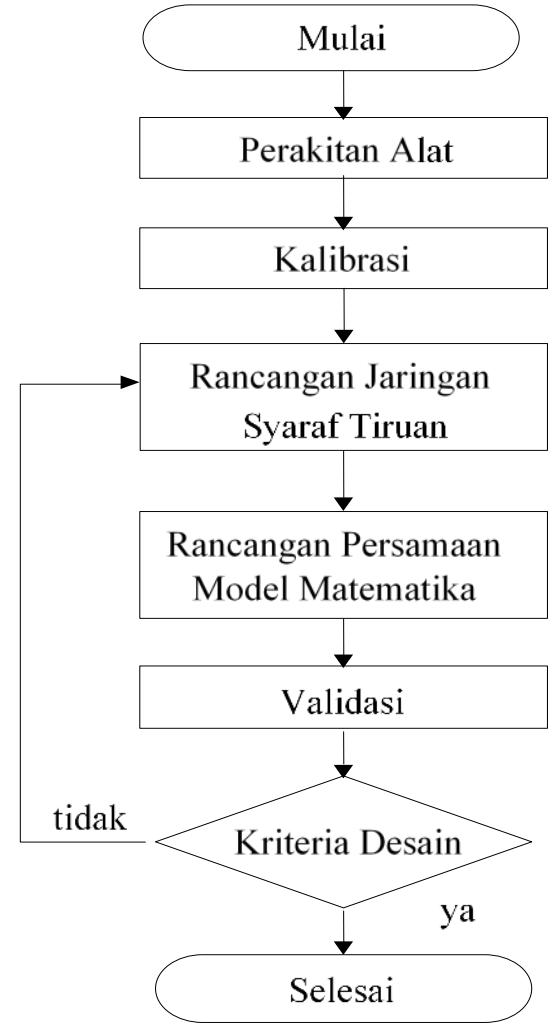

Gambar 2. Diagram Prosedur Penelitian 
Setelah perancangan struktur JST Backpropagation selesai dirancang, langkah selanjutnya adalah perancangan proses pembelajaran JST Backpropagation. Proses pembelajaran dimulai dari perancangan proses training seperti diperlihatkan pada Gambar 3.

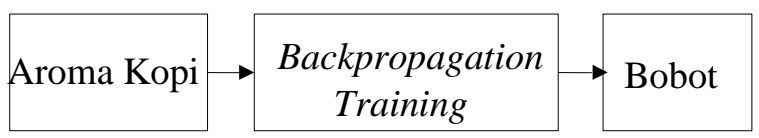

Gambar 3. Proses training backpropagation

Setelah proses training di atas terselesaikan, didapatkan nilai bobot input, nilai bobot hidden, dan nilai bobot Output. Proses training dapat membutuhkan waktu yang banyak karena perancangan sistem yang harus mencapai target yang diberikan.

Tahapan selanjutnya adalah proses identifikasi setiap jenis kopi. Pada penelitian ini digunakan 5 jenis kopi yaitu: kopi natural robusta Lampung (kopi 1), robusta natural (kopi 2), robusta semi wash (kopi 3), natural arabika (kopi 4), arabika full wash (kopi 5). Proses ini dilakukan dengan mendeteksi aroma tiap jenis kopi sehingga mendapatkan kriteria nilai sensor yang akan menjadi bantuan untuk JST dalam mengidentifikasi jenis kopi.

\section{Pembentukan Persamaan Matematika dari Model JST yang Dihasilkan}

Pembentukan persamaan model matematika dilakukan dengan menghitung ulang bobot dan bias yang telah didapatkan dari fungsi aktivasi terbaik dengan ketentuan perhitungan sebagai berikut:

1. Persamaan fungsi aktivasi logsig adalah

$$
\mathrm{y}=1 /(1+\exp (-\mathrm{x}))
$$

2. Persamaan fungsi aktivasi tansig:

$$
y=(1-\exp (-2 x)) /(1+\exp (-2 x))
$$

3. Persamaan fungsi aktivasi purelin adalah:

$$
\mathrm{y}=\mathrm{x}
$$

\section{Penginputan Model Persamaan Matematika Ke dalam Mikrokontroler}

Model persamaan matematika yang telah dihitung akan dimasukkan ke dalam mikrokontroler untuk melakukan validasi aktual terhadap setiap jenis kopi. Di dalam program arduino dibuat klasifikasi setiap jenis kopi berdasarkan nilai JST yang didapatkan sehingga dapat mempermudah pengelompokan setiap jenis kopi.

\section{Rancangan Pengambilan Data}

Tahapan pengambilan data dapat dilihat pada Gambar 4.

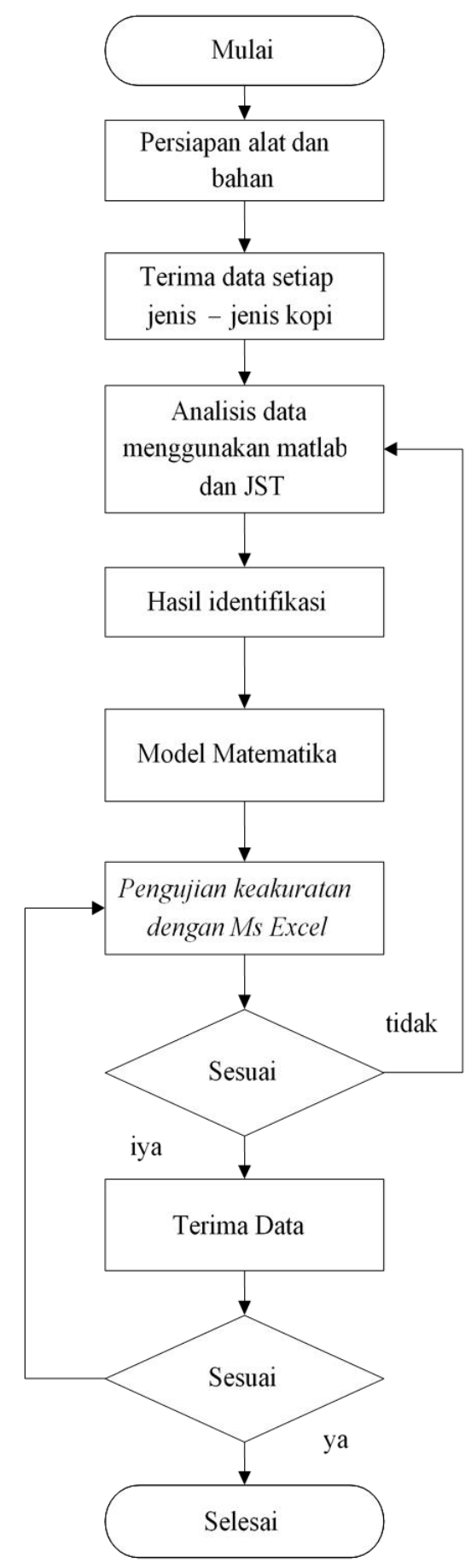

Gambar 4. Prosedur Penelitian 


\section{Analisis Data}

Data yang didapatkan dari hasil penelitian akan dianalisis untuk melihat Koefesien Determinan $\left(\mathrm{R}^{2}\right)$ dan Root Mean Square Error (RMSE).

\section{Koefisien Determinan $\left(\mathbf{R}^{\mathbf{2}}\right)$}

Besarnya kontribusi variabel bebas terhadap variabel terikat ditentukan menggunakan Koefisien Determinasi. Nilai determinasi terletak diantara 0 dan 1 . Nilai koefesien determinasi mendekati 1 saat semua nilai obesevasi terletak sangat dekat dengan garis regresi. Nilai koefesien determinasi semakin kecil saat nilai observasi semakin menjauh dan berpencar. Untuk mengetahui seberapa besar nilai koefesien determinasi maka perlu dilakukan pengeplotan grafik antara jenis jenis kopi menggunakan nilai prediksi sebagai variabel tergantung (Y) dengan nilai validasi sebagai variabel bebas $(X)$ dengan menggunakan software Microsoft Excel (Dewangga \& Laksito, 2015).

\section{Root Mean Square Error (RMSE)}

RMSE adalah metode alternatif untuk mengevaluasi teknik peramalan yang digunakan untuk mengukur tingkat akurasi hasil prakiraan suatu model. RMSE merupakan nilai rata-rata dari jumlah kuadrat kesalahan, yang juga menyatakan ukuran besarnya kesalahan yang dihasilkan oleh suatu model prakiraan. Nilai RMSE rendah menunjukkan bahwa variasi nilai yang dihasilkan oleh suatu model prediksi mendekati variasi nilai obeservasinya. Akar kesalahan kuadrat rata-rata (Root Mean Square Error) merupakan suatu ukuran kesalahan yang didasarkan pada selisih antara dua nilai yang didefinisikan pada persamaan 4 .

$\operatorname{RMSE}=\left|\sum_{i} \sum_{d} \sqrt{\frac{\left(\hat{T}_{i d}-T_{i d}\right)^{2}}{N .(N-1)}}\right|$

(untuk $\boldsymbol{i} \neq \boldsymbol{d}$ )
Perhitungan deviasi standar dari selisih kedua nilai tersebut didefinisikan pada persamaan 5 .

$\sigma=\left|\sum_{i} \sum_{d} \sqrt{\frac{\left(\widehat{T}_{i d}-T_{i d}\right)^{2}}{N .(N-1)-1}}\right|$

(untuk $\mathbf{i} \neq \mathbf{d}$ )

Dapat dilihat bahwa untuk nilai $\mathrm{N}$ yang besar, persamaan kedua rumus akan menghasilkan nilai yang bisa dikatakan sama. RMSE bisa disebut sebagai deviasi standar $(\sigma)$ atau sebaliknya.

Indikator RMSE dan $\sigma$ tidak dapat membandingkan sebuah model yang sama jika diterapkan pada kajian yang berbeda, karena nilai-nilainya tergantung pada ukuran besarnya matriks, T dan sebagainya. Persentase dari akar kesalahan kuadrat ratarata (\% RMSE) dapat didefinisikan sesuai persamaan 6 .

$\% \mathrm{RMSE}=\frac{\mathrm{RMSE}}{T_{1}} \times 100 \%$

Dalam bentuk yang identik koefisien variasi $\mathrm{Cv}$ (coefficient of variation) didefenisikan melalui persamaan 7 dan 8 .

$C_{v}=\frac{\sigma}{T_{1}} \times 100 \%$

$T_{1}=\frac{1}{N .(N-1)} \sum_{i} \sum_{d} T_{i d}$ untuk $i \neq d \ldots \ldots$

Semakin kecil nilai RMSE, \%RMSE, $\sigma$, dan $\mathrm{Cv}$ berarti hasil estimasi model yang dihasilkan semakin tinggi saat dibandingkan dengan pengamatan.

\section{HASIL DAN PEMBAHASAN}

\section{Hasil Perancangan Sensor E-Nose}

Hasil dari perancangan sensor E-Nose yaitu berupa sensor gas yang diletakkan di dalam kotak akrilik dengan ukuran $15 \mathrm{~cm}$ dan ruang chamber dengan ukuran $15 \mathrm{~cm} \mathrm{x}$ $15 \mathrm{~cm} \times 22 \mathrm{~cm}$. 


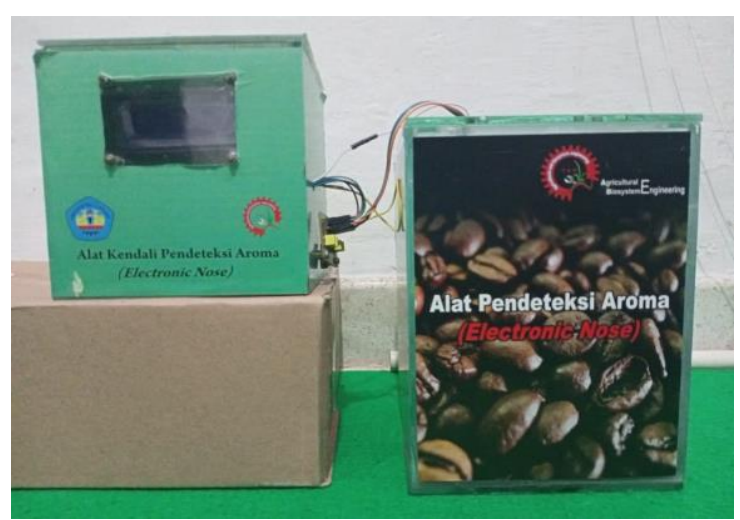

Gambar 5. Ruang Kendali dan chamber sensor electronic nose

\section{Hubungan antara nilai sensor dan jenis kopi}

Hubungan nilai sensor dengan jenis kopi dapat dilihat pada Gambar 6. Hasil ini menampilkan perbandingan antara nilai sensor (ADC) dengan jenis-jenis kopi. Pengukuran dilakukan dengan menggunakan empat jenis sensor yang diletakkan di dalam kotak kaca di sekitar biji kopi pengamatan. Terdapat perbedaan rentang nilai pada empat jenis sensor dari setiap jenis kopi.

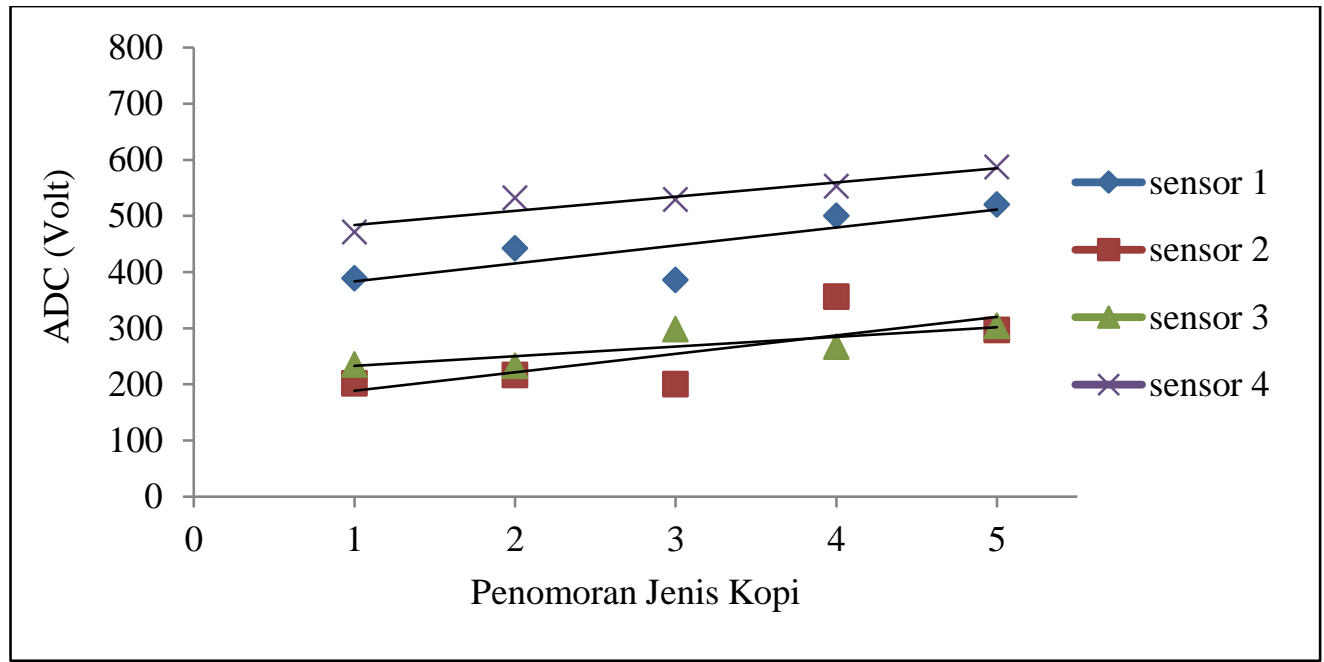

Gambar 6. Hubungan nilai sensor ADC (sumbu y) dengan jenis kopi (sumbu x)

Pada jenis kopi pertama rentang nilai sensor ADC 1 antara 389-474, ADC 2 antara 202-301, ADC 3 antara 235-332, ADC 4 471-551. Pada jenis kopi kedua rentang nilai sensor ADC 1 antara 442-547, ADC 2 antara 217-394, ADC 3 antara 233351, ADC 4 antara 532 - 607. Pada jenis kopi ketiga rentang nilai sensor ADC 1 antara 386-520, ADC 2 antara 200-249, ADC 3 antara 298-399, ADC 4 antara 529617. Pada jenis kopi ke-empat rentang nilai sensor ADC 1 antara 500-597, ADC 2 antara 356-521, ADC 3 antara 267-364, ADC 4 antara 553-637. Pada jenis kopi kelima rentang nilai sensor ADC 1 antara 520-636, ADC 2 antara 297-506, ADC 3 antara 304-431, ADC 4 antara 587-670.

\section{Pengembangan Model Jaringan Syaraf Tiruan}

Pengembangan model JST dilakukan dengan melakukan 2 langkah yaitu pelatihan dan pengujian. Pelatihan model JST merupakan salah satu langkah dalam melakukan pengembangan model JST. Pelatihan ini merupakan tahapan proses kalibrasi sensor untuk menentukan model JST. Pelatihan model JST dilakukan dengan cara menggunakan Software Matlab. Hal pertama yang dilakukan adalah melakukan input data dari hasil pengamatan untuk diolah menggunakan JST.

Pelatihan model JST yang dilakukan menggunakan dua hidden layer dengan node 3-3-1, learning rate 0,001 , dan tipe pelatihan tranlm. Proses pelatihan dilakukan menggunakan 27 variasi fungsi 
aktivasi dari varian rumus matematika logsig, tansig, purelin. Setelah pelaksanaan input data, tahap selanjutnya adalah memasukkan variasi fungsi aktivasi ke dalam software MATLAB dan menekan tombol running pada software.

Nilai koefisien determinasi $\left(\mathrm{R}^{2}\right)$ yang tinggi dan nilai Root Mean Square Error (RMSE) yang rendah mengindikasikan bahwa model tersebut merupakan model terbaik. Pada JST, nilai $\mathrm{R}^{2}$ yang tinggi dan RMSE yang kecil yang menjadi pilihan. Hasil proses pelatihan model JST yang telah dilakukan. fungsi aktivasi logsig, logsig, tansig menunjukkan nilai RMSE yang kecil dan nilai $\mathrm{R}^{2}$ yang mendekati 1 .

Pengujian model JST merupakan hal selanjutnya yang dilakukan setelah pelatihan model JST. Pengujian model JST dilakukan sama halnya dengan pelatihan model JST. Data prediksi merupakan keluaran yang dihasilkan oleh pengujian model JST. Fungsi aktivasi terbaik diambil berdasarkan nilai RMSE terkecil dan koefesien determinasi $\left(\mathrm{R}^{2}\right)$ terbesar pada pengujian model JST. Hasil data pengujian memiliki model yang akurat dengan nilai $\mathrm{R}^{2}$ yang didapatkan adalah 0,991, sedangkan nilai RMSE yang didapat adalah 0,003602368 dengan fungsi aktivasi logsig, logsig, tansig. Hal tersebut menunjukkan bahwa model prediksi tersebut akurat dalam memprediksi jenis - jenis kopi.

\section{Persamaan Matematika dari Pengembangan Model Jaringan Syaraf Tiruan}

Salah satu tujuan penelitian ini adalah mendapatkan persamaan model matematika yang dihasilkan dari proses pengembangan model JST. Nilai bobot dan bias diperlukan untuk mendapatkan persamaan model matematika. Nilai bobot dan bias didapat dari hasil menjalankan fungsi aktivasi terbaik di dalam JST. Persamaan model matematika dicari dengan menggunakan bobot dan bias yang telah terekam setelah pengembangan model JST. Sebelum menggunakan persamaan matematika dari bobot dan bias, harus dilakukan normalisasi nilai input tiap sensor terlebih dahulu.

Normalisasi merupakan penskalaan terhadap nilai-nilai input dan target hingga nilai-nilai tersebut masuk dalam suatu range tertentu yang disebut preprocessing atau normalisasi data (Chandra, et al., 2016). Proses perhitungan normalisasi didapat dengan cara membagi nilai $\mathrm{Xi}$ (input) dengan nilai input yang paling besar $(\mathrm{Xb})$.

Nilai input yang telah dinormalisasi kemudian dimasukkan ke dalam persamaan model matematika yang telah didapatkan dari pengembangan model JST. Tabel 1, 2, dan 3 menunjukkan persamaan model matematika yang didapat dari hasil bobot dan bias setelah melakukan pengembangan model JST.

Tabel 1. Persamaan Hidden Layer 1

\begin{tabular}{|c|c|}
\hline & Persamaan Hidden Layer 1 \\
\hline 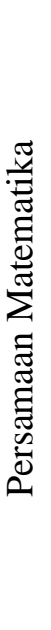 & 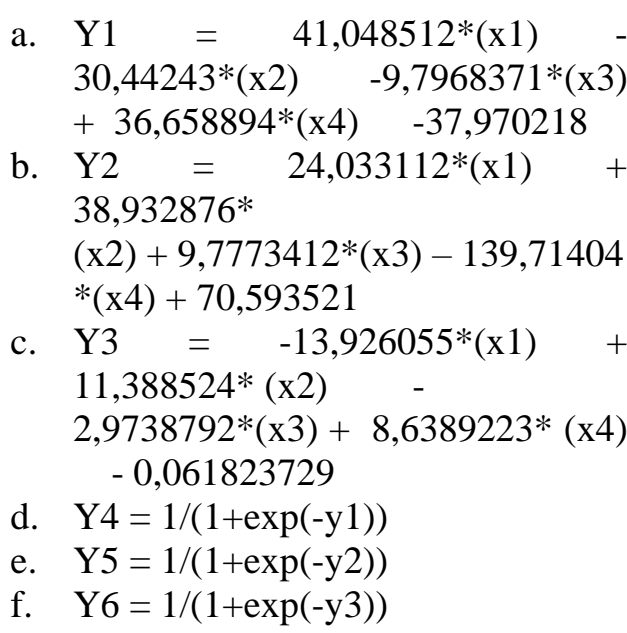 \\
\hline 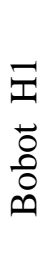 & 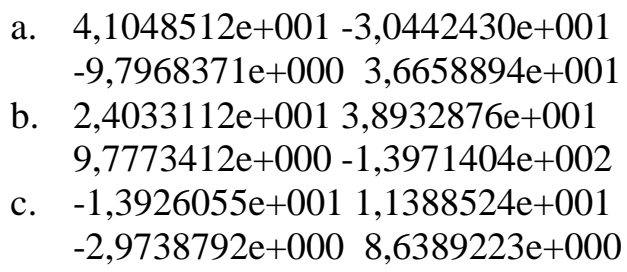 \\
\hline 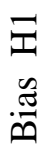 & $\begin{array}{ll}\text { a. } & -3,7970218 \mathrm{e}+001 \\
\text { b. } & 7,0593521 \mathrm{e}+001 \\
\text { c. } & -6,1823729 \mathrm{e}-002\end{array}$ \\
\hline
\end{tabular}


Pada Tabel 1, fungsi aktivasi yang digunakan adalah logsig, sehingga didapatkan perubahan nilai Y4 hingga Y6 mengikuti $\mathrm{y}=1 /(1+\exp (-\mathrm{x}))$. Persamaan pada Tabel 2 fungsi aktivasinya adalah logsig, sehingga terjadi perubahan nilai Y10 - Y12 mengikuti persamaan $\mathrm{y}=1 /(1+\exp (-\mathrm{x}))$. Persamaan pada Tabel 3 memiliki fungsi tansig, sehingga terdapat perubahan pada nilai Y13 dan Y14 mengikuti rumus $\mathrm{y}=(1-\exp (-2 \mathrm{x})) /(1+\exp (-$ $2 \mathrm{x})$ ).

Tabel 2. Persamaan Hidden Layer 1-2

\begin{tabular}{|c|c|}
\hline & Persamaan Hidden Layer 1-2 \\
\hline 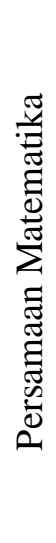 & $\begin{array}{ll}\text { a. } & \mathrm{Y} 7=153,44313 *(\mathrm{y} 4)+ \\
& 100,26152 *(\mathrm{y} 5)+ \\
& 39,321225^{*}(\mathrm{y} 6)-177,94293 \\
\text { b. } & \mathrm{Y} 8=12,348554 *(\mathrm{y} 4)+ \\
& 3,3155519^{*}(\mathrm{y} 5)+ \\
& 53,723096^{*}(\mathrm{y} 6)-53,115088 \\
\text { c. } & \mathrm{Y} 9=23,973155 *(\mathrm{y} 4)+ \\
& 80,165 *(\mathrm{y} 5)+39,091537 *(\mathrm{y} 6)- \\
& 43,732103 \\
\text { d. } & \mathrm{Y} 10=1 /(1+\exp (-\mathrm{y} 7)) \\
\text { e. } & \mathrm{Y} 11=1 /(1+\exp (-\mathrm{y} 8)) \\
\text { f. } & \mathrm{Y} 12=1 /(1+\exp (-\mathrm{y} 9))\end{array}$ \\
\hline 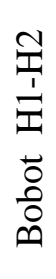 & $\begin{array}{ll}\text { a. } & 1,5344313 \mathrm{e}+0021,0026152 \mathrm{e}+002 \\
& 3,9321225 \mathrm{e}+001 \\
\text { b. } & 1,2348554 \mathrm{e}+0013,3155519 \mathrm{e}+000 \\
& 5,3723096 \mathrm{e}+001 \\
\text { c. } & 2,3973155 \mathrm{e}+0018,0165000 \mathrm{e}+001 \\
& 3,9091537 \mathrm{e}+001\end{array}$ \\
\hline 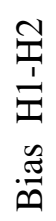 & $\begin{array}{ll}\text { a. } & -1,7794293 \mathrm{e}+002 \\
\text { b. } & -5,3115088 \mathrm{e}+001 \\
\text { c. } & -4,3732103 \mathrm{e}+001\end{array}$ \\
\hline
\end{tabular}

Tabel 3. Persamaan Hidden Layer 2

\begin{tabular}{|c|c|}
\hline \multicolumn{2}{|c|}{ Persamaan Hidden Layer 2} \\
\hline 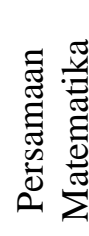 & $\begin{array}{ll}\text { a. } & \mathrm{Y} 13=37,398977 *(\mathrm{~B} 13)+ \\
& 0,95055342 *(\mathrm{~B} 14)-0,49542024 \\
& *(\mathrm{~B} 15)+0,69859456 \\
\text { b. } & \mathrm{Y} 14=(1-\exp (-2 * \mathrm{y} 13)) /(1+\exp (-2 * \\
& \mathrm{y} 13))\end{array}$ \\
\hline $\begin{array}{l}\overrightarrow{0} \\
\stackrel{0}{0} \\
0\end{array}$ & $\begin{array}{l}3,7398977 \mathrm{e}+0019,5055342 \mathrm{e}-001 \\
-4,9542024 \mathrm{e}-001\end{array}$ \\
\hline 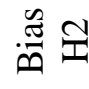 & 6,9859456e-001 \\
\hline
\end{tabular}

Setelah mendapatkan Y14 atau nilai akhir (Ya), langkah selanjutnya adalah mengembalikan nilai-nilai yang ternormalisasi terlebih dahulu ke nilai aslinya untuk mendapatkan nilai pada range yang sebenarnya (denormalisasi). Proses perhitungan denormalisasi didapatkan dengan cara pengalian antara nilai akhir dengan nilai Output paling besar (Yb). Sebagai contoh, Output dalam penelitian ini ialah jenis-jenis kopi, dan nilai Output paling besar ialah 5 .

Setelah dilakukan normalisasi nilai dari hasil keseluruhan model matematika, maka nilai dan persamaan inilah yang diinput ke dalam mikrokontroller melalui program Arduino.

\section{Klasifikasi jenis kopi dan Integrasi Model JST Ke dalam Mikrokontroller}

Setelah didapatkan hasil pelatihan dan pengujian terbaik dengan menggunakan model JST dan Software Matlab maka langkah selanjutnya yaitu mengklasifikasi tiap jenis kopi berdasarkan hasil JST yang telah didapat, yaitu:

1. Nilai 0-1 untuk jenis kopi 1 (natural robusta Lampung)

2. Nilai 1,01-2 untuk jenis kopi 2 (natural robusta)

3. Nilai 2,01-3 untuk jenis kopi 3 (robusta semiwash)

4. Nilai 3,01-4 untuk jenis kopi 4 (natural arabika) 
5. Nilai 4,01-5 untuk jenis kopi 5 (arabika fullwash)

Integrasi Model JST dengan mikrokontroller dilakukan dengan cara memasukkan rumus model matematika yang telah didapatkan ke dalam mikrokontroller dengan bantuan software arduino. Proses pemrograman yang digunakan pada arduino untuk pemasukkan rumus model matematika menggunakan pemrograman bahasa $\mathrm{C}$ sederhana. Nilai akhir dari rumus model matematika perlu dilakukan juga proses normalisasi kembali yaitu dengan pengalian nilai tertinggi dari nilai Output.

Setelah proses input model matematika, tekan tombol verify dan uploading di dalam Arduino untuk mengetahui bahwa bahasa $\mathrm{C}$ yang digunakan tidak memiliki kesalahan. Headline berwarna kuning/merah akan muncul apabila terjadi kesalahan pada proses tersebut yang menunjukan adanya error pada proses pemrograman. Pemeriksaan pada taskbar tools pada Software Arduino perlu dilakukan untuk memastikan port dan board pada Arduino telah terpasang dan terkoneksi dengan komputer. Hal ini untuk meminalisir kesalahan dalam proses upload.

\section{Validasi Rancangan Alat Sensor}

Pada tahap validasi proses ini dilakukan dengan memberikan pola data baru yang didapatkan dengan menggunakan program validasi dari hasil proses pelatihan dan pengujian dalam model JST. Perhitungan dan grafik statistik hasil validasi dilakukan dengan menggunakan Software Microsoft Excel 2007. Pengujian dilakukan bertujuan untuk mengetahui tingkat keakuratan JST yang telah dibuat. Gambar 7-11, merupakan grafik validasi setiap jenis kopi dengan keterangan:

1. Kopi 1 Robusta Lampung memiliki nilai rentang $0,01<y \leq 1,00$

2. Kopi 2 Natural Robusta $1,01<y \leq 2,00$

3. Kopi 3 Robusta Semiwash $2,01<y \leq 3,00$
4. Kopi 4 Natural Arabika $3,01<\mathrm{y} \leq 4,00$

5. Kopi 5 Arabika Fullwash $4,01<\mathrm{y} \leq 5,00$

Gambar 7 menunjukkan validasi nilai aroma kopi pertama yaitu robusta lampung selama 25 menit. Nilai validasi menunjukkan kopi 1 yang memiliki arti bahwa nilai validasi sudah sesuai. Gambar 8 menunjukkan validasi kopi 2 yaitu natural robusta dengan rentang nilai validasi berada diantara 1 dan 2. Nilai tersebut sudah sesuai dengan perhitungan pada JST dan membuktikan bahwa hasil validasi tersebut menunjukkan kopi natural robusta.

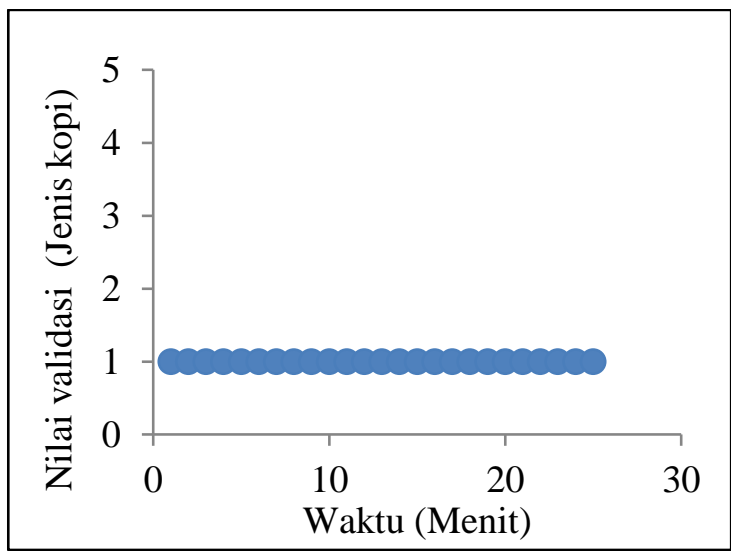

Gambar 7. Validasi kopi 1 atau kopi robusta Lampung

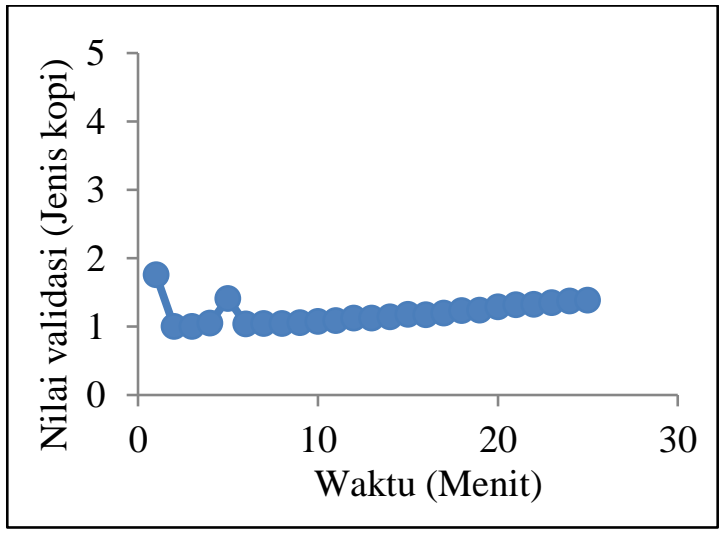

Gambar 8. Validasi kopi 2 atau kopi natural robusta 


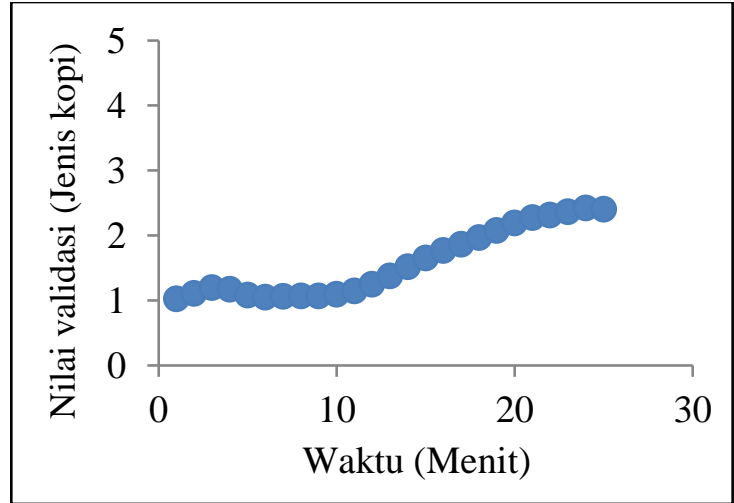

Gambar 9. Validasi kopi 3 atau kopi robusta semiwash

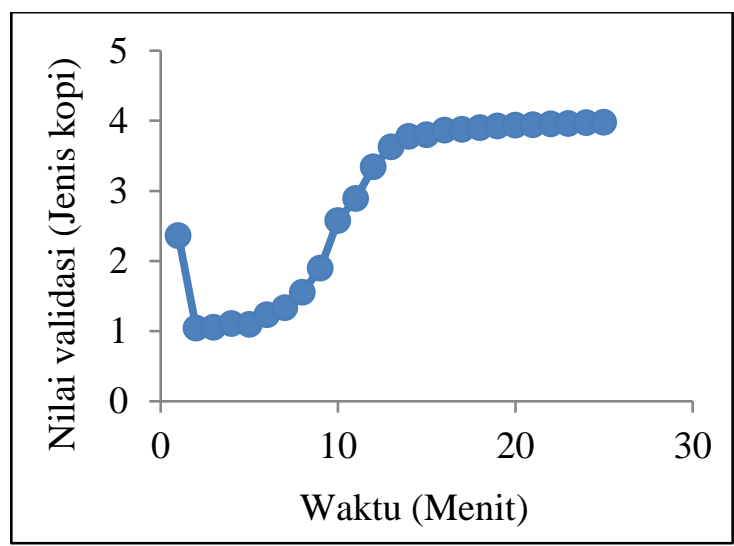

Gambar 10. Validasi kopi 4 atau kopi arabika natural

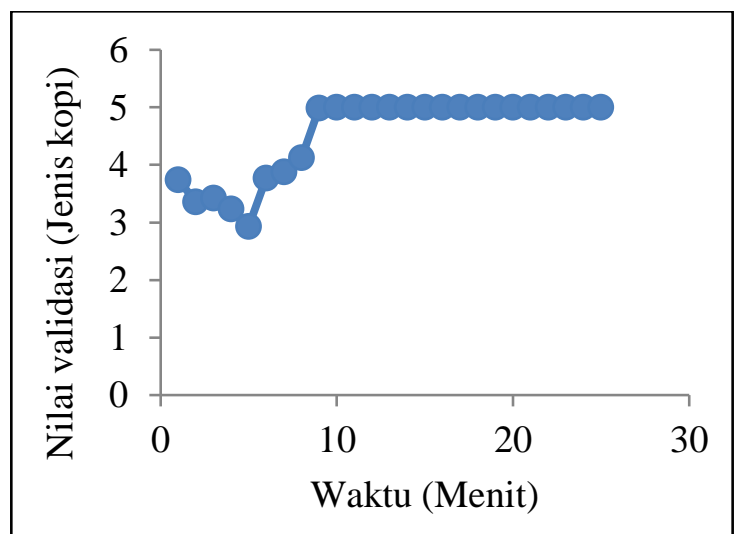

Gambar 11. Validasi kopi 5 atau kopi arabika fullwash

Gambar 9 menunjukkan validasi kopi 3, yaitu robusta semiwash. Dilihat dari Gambar 9, nilai kopi yang menunjukkan robusta semiwash berada pada rentang 1525 menit. Gambar 10 menunjukkan validasi kopi 4, yaitu arabika natural; nilai validasi menunjukkan kopi arabika natural pada waktu 15-25 menit. Gambar 11 menunjukkan validasi kopi 5, yaitu arabika fullwash; dapat dilihat rentang waktu yang menunjukkan nilai arabika fullwash berada pada menit 10-25 menit. Berdasarkan gambar 7-11 waktu identifikasi terbaik terletak pada menit ke 15-25.

Berdasarkan gambar 7-11 dapat disimpulkan bahwa rata-rata persentase keberhasilan identifikasi 5 jenis kopi, yaitu kopi natural robusta lampung (Kopi 1) yaitu $100 \%$, kopi natural robusta (Kopi 2) $100 \%$, kopi robusta semiwash (Kopi 3) $72 \%$, kopi arabika natural (Kopi 4) 100\%, dan kopi arabika fullwash (Kopi 5) $100 \%$.

\section{KESIMPULAN DAN SARAN}

\section{Kesimpulan}

Kesimpulan dari penelitian adalah JST telah disusun menggunakan arsitektur 4 layer. Layer 1, yaitu 4 input, layer 2 memiliki 3 node, layer 3 memiliki 3 node, layer 4 memiliki 1 Output (keluaran). Fungsi aktivasi terbaik ialah logsig-logsigtansig dengan nilai RMSE sebesar 0,003602368 dan $R^{2}$ sebesar 0,991 . Nilai ADC (tegangan sensor) terendah terdapat pada sensor MQ 136, yaitu 202 untuk mendeteksi kopi robusta lampung dan ADC tertinggi dari sensor TGS 2602 yaitu 670 yang mendeteksi aroma kopi robusta semiwash. Klasifikasi jenis kopi telah dilakukan menggunakan sensor E-Nose dengan metode Backpropagation menunjukkan hasil cukup baik terutama pada identifikasi di waktu menit ke 15-25. Hal ini dapat dilihat dari rata-rata persentase keberhasilan identifikasi 5 jenis kopi pada menit ke 15-25, yaitu: kopi natural robusta lampung (Kopi 1) 100\%, kopi natural robusta (Kopi 2) 100\%, kopi robusta semiwash (Kopi 3) 72\%, kopi arabika natural (Kopi 4) 100\%, dan kopi arabika fullwash (Kopi 5) 100\%.

\section{Saran}

Perlu adanya penelitian lanjutan dari hasil yang didapat untuk mengidentifikasi jenis kopi dengan sensor lain yang lebih peka terhadap kandungan gas yang dikeluarkan oleh biji kopi. Sehingga dapat 
dihasilkan perbandingan nilai prediksi JST dalam sensor yang berbeda.

\section{UCAPAN TERIMA KASIH}

Peneliti mengucapkan terimakasih Kepada LPPM Universitas Lampung atas bantuan pendanaan penelitian tentang aplikasi $E$-Nose pada pendeteksian keaslian kopi luwak yang telah selesai dilaksanakan.

\section{DAFTAR REFERENSI}

Arwangga, A. F., Asih, I. A. R. A., \& Sudiarta, I. W. (2016). Analisis Kandungan Kafein pada Kopi di Desa Sesaot Narmada menggunakan Spektrofotometri UV-Vis. Jurnal Kimia (Journal of Chemistry), 10(1), 110-114.

Baskara, S., Lelono, D., \& Widodo, T. W. (2016). Pengembangan Hidung Elektronik untuk Klasifikasi Mutu Minyak Goreng dengan Metode Principal Component Analysis. IJEIS (Indonesian Journal of Electronics and Instrumentation Systems), 6(2), 221-230.

Briandet, R., Kemsley, E. K., \& Wilson, R. H. (1996). Discrimination of Arabica and Robusta in instant coffee by Fourier transform infrared spectroscopy and chemometrics. Journal of Agricultural and Food Chemistry, 44(1), 170-174.

Chandra, M., Sovia, R., \& Permana, R. (2016). Analisis Metode Backpropagation Untuk Memprediksi Indeks Harga Saham Indofood Sukses Makur TBK. (INDF). Komputer Teknologi Informasi, 2(1), 47-61.

Dewangga, A., \& Laksito, H. (2015). Faktor-faktor yang berpengaruh terhadap audit report lag. Diponegoro Journal of Accounting, 4(3), 1-8.
Fitryadi, K., \& Sutikno, S. (2016). Pengenalan Jenis Golongan Darah Menggunakan Jaringan Syaraf Tiruan Perceptron. Jurnal Masyarakat Informatika, 7(1), 1-10.

Guntoro, H., \& Somantri, Y. (2013). Rancang bangun magnetic door lock menggunakan keypad dan solenoid berbasis mikrokontroler arduino uno. Jurnal Electrans, 12(1), 39-48.

Ikhsan, M. A. (2018). Pendeteksi Kekeruhan Air di Tandon Rumah Berbasis Arduino Uno. Jurnal Qua Teknika, 8(2), 17-29.

Kusumadewi, S. (2004). Membangun Jaringan Syaraf Tiruan: Graha Ilmu.

Lelono, D., \& Chairiawan, M. A. (2013). Karakterisasi Pola Aroma Salak Pondoh dengan E-Nose Berbasis Sensor Metal Oksida. IJEIS (Indonesian Journal of Electronics and Instrumentation Systems), 3(1), 71-82.

Matondang, Z. A. (2013). Jaringan Syaraf Tiruan dengan Algoritma Backpropagation untuk penentuan kelulusan sidang skripsi. Pelita Inform. Budi Darma, 4(1), 84-93.

Puspitaningrum, D. (2006). Pengantar jaringan syaraf tiruan.

Rabersyah, D. (2016). Identifikasi Jenis Bubuk Kopi menggunakan Electronic Nose dengan Metode Pembelajaran Backpropagation. Jurnal Nasional Teknik Elektro, 5(3), 333-338.

Sitohang, M. E. (2012). Analisis Sinyal Electronic Nose Berbasis Wavelet Menggunakan Support Vector Machine untuk Identifikasi Jenis Teh Hitam. Jurnal Sistem Komputer, 2(2), 47-53. 
Telaumbanua, M., Novita, D. D., Triyono, S., Saragih, C. 2021. Tipe chamber dan posisi sensor e-nose untuk mendeteksi aroma biji kopi robusta menggunakan mikrokontroler. Jurnal Ilmiah Rekayasa Pertanian dan Biosistem, 9(1), 84-95.

Toko, K. (2000). Biomimetic sensor technology. Cambridge University Press.
Wuryandari, M. D., \& Afrianto, I. (2012). Perbandingan Metode Jaringan Syaraf Tiruan Backpropagation Dan Learning Vector Quantization Pada Pengenalan Wajah. Jurnal Komputer Dan Informatika (Komputa), 1(1), 45-51. 